\title{
Discussion: Foundation and structural design of the Bibliotheca Alexandrina
}

\section{Hamza and M. Ghoneim}

\section{R. A. M. Watkins, FKW Ltd and S. K. Ng, Babtie Asia Ltd} The authors' paper deals with an important and unusual structure, and in many ways it would have been interesting to have had greater description of the construction process in addition to the design considerations that are dealt with in the paper. Nonetheless, the paper brings to mind some topics that are relevant to the design of structures elsewhere that are intended to be public and monumental in character.

The authors suggest that the design life for the building is 200 years, and rightly point out that the proximity of the sea is a threat to its longevity. As the authors will be aware, codes of practice worldwide are in some disarray about the ways in which the durability of concrete should be ensured. It is probably right to say that no code deals explicitly with design lives as long as 200 years, and even such structures as the Channel Tunnel, ${ }^{1}$ the Storebaelt Tunnel ${ }^{2}$ and the Tsing Ma Bridge $^{3}$ have explicit design lives limited to 100 or 120 years. Most international codes and standards generally adopt prescriptive measures to achieve levels of durability of concrete for different exposure conditions. However, the development of the different codes is not consistent. The provisions for durability in ACI $318,{ }^{4}$ to which the authors refer in the paper, are perhaps not as comprehensive as those in other comparable codes. Emphasis is given to the requirements for freezing conditions, which would not be relevant for Egypt. Probably the most comprehensive and up-to-date requirements are those that are set out in EN 206, ${ }^{5}$ but this code has only recently been issued.

Many investigations into the influence of climate on concrete have been concerned with temperate climates (such as Europe) or with hot, dry climates. ${ }^{6}$ However, Alexandria, although in a region of the world that would normally be considered as a hot, dry area, has a marine environment and, because of the Mediterranean influence, has a temperature and humidity range that is significantly different from typical hot, dry areas. It might be expected that these differences in climate would lead to differences in the long-term performance of concrete. Higher rates of evaporation of moisture from exposed or insufficiently protected concrete surfaces may occur in Alexandria when compared with more temperate areas. However, during certain times of the year, local curing may be sensitive to a combination of low humidity and relatively high daytime temperatures. The proximity to the sea brings shortterm climatic changes from wetting to drying phases, which may allow a greater potential for chlorides to be 'sucked' into the surface of the concrete.

It would be interesting if the authors could expand upon the design provisions they made for durability. Specifically, it would be interesting to see what limits were set on the concrete cover for the different concrete elements, the limits on aggregate type and qualities, and concrete mix proportions. Did they use or consider the use of cement replacement, particularly for the thick raft/pile cap used at the fourth basement level, where temperature rises during construction may be large? Were any specific limits set on the water/cement content of the concrete? Did durability concerns control the section sizes of any elements? Were any special protective coatings applied to either reinforcing steel or concrete to enhance the durability?

Although the mechanisms by which chloride ions penetrate concrete are complex and not fully understood, it is generally accepted that chloride ions in solution penetrate the concrete initially by sorption, followed by diffusion of the chloride ions through the concrete. When the chloride concentration at the reinforcement reaches a critical value, which is dependent on a number of factors, local corrosion of the reinforcement can occur. Chemical interactions also occur between the chlorides and the hydration products, which bind some of the chlorides so that they are not available to induce corrosion. Some researchers have developed analytical models that track the development of critical chloride concentrations through the concrete section with time. Bearing in mind the very long design life, did the authors attempt to model the concrete for the library in this way?

Dealing specifically with the basement (which obviously forms a substantial part of the structure), we note from Fig. 8 in the paper that a continuous waterproof membrane is shown under the basement raft and between the outer basement wall and the diaphragm wall. This membrane is described as 'a continuous drained waterproof membrane'. It is not clear how this membrane functions, or how any drainage is provided. Are any water pressure monitoring devices provided on the inside of this membrane, and are any monitoring devices contained 
within the inspection cells that form part of the cellular raft? Does the waterproofing system rely only on passive means of protection; that is, the membrane and the intrinsic impermeability of the concrete, or have other active measures such as permanent pumping provisions been made? Were any criteria set for leakage of water or moisture through the diaphragm walls in the temporary condition? Was leakage either through the diaphragm wall or through the final outer basement wall a problem during or after construction?

In some cases where long-term durability is required, it has been recognised that, in the long term, chloride ingress or carbonation or both may occur, and provision has been made within the concrete for near-surface instrumentation that would allow the reduction in passivity of the concrete to be monitored. Additionally, provision for the future installation of remedial measures, such as active cathodic protection, has sometimes been made at the initial construction phase. Did the authors consider the need for any such monitoring or measures for future remediation work?

We were interested to see the form of construction adopted for the retaining structure. The diaphragm wall construction reminded one of us of the form of construction adopted for parts of the Royal Seaforth Dock, Liverpool, and the dock passage. ${ }^{7,8}$ In that project there was the same requirement to retain a large depth of ground (in that case up to about $18 \mathrm{~m}$ and extending for about $1500 \mathrm{~m}$ in plan) while bulk excavation was carried out inside the retaining structure. In a major part of the work the diaphragm walls were arched and had a posttensioned rear fin wall tied down to the rock below. For other sections the diaphragm walls were similar to the T-shaped section shown on the straight side of the Alexandria Library.

However, we were also reminded of a more recent smaller project with which we were both involved in Hong Kong. For this project, the retained height of the diaphragm wall was about $11 \mathrm{~m}$. We had the same restriction on the use of ground anchors as at Alexandria. For that project, after consideration of alternatives including the use of vertical post-tensioning, we adopted the use of three levels of internal raking props supported on internal foundations (see Fig. 11). The working

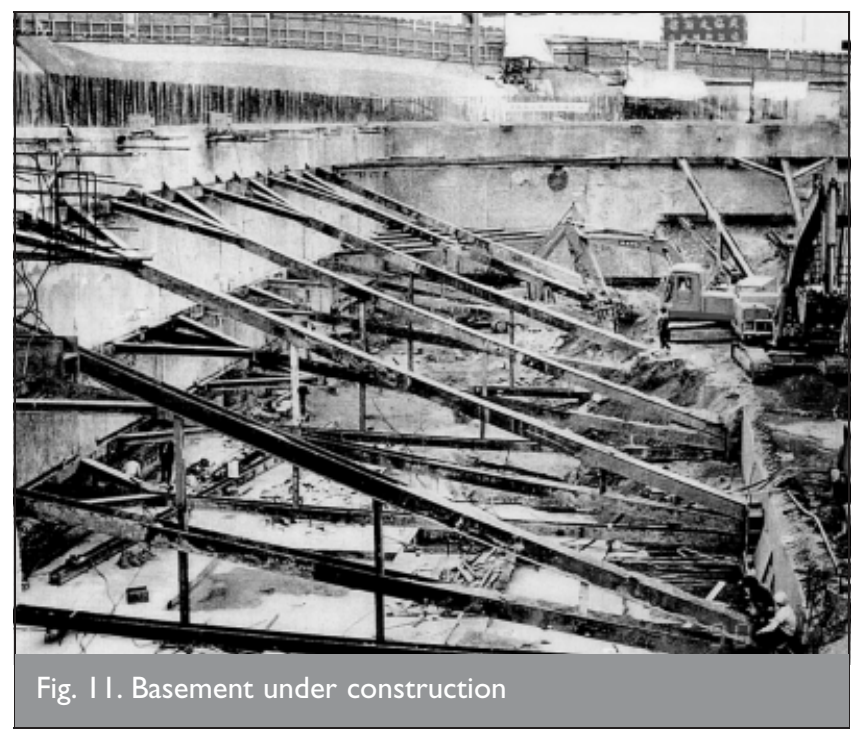

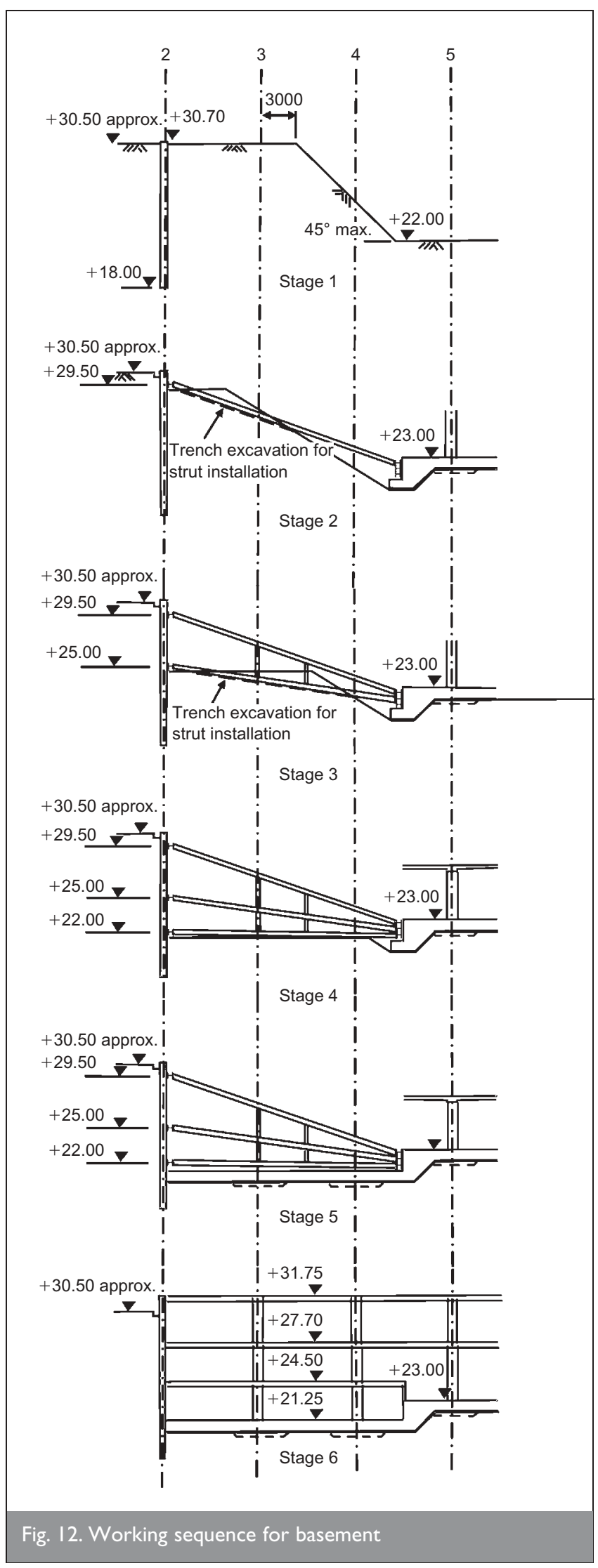

sequence that we devised (see Fig. 12) allowed bulk excavation and basement construction to be started prior to the full completion of the diaphragm wall. It appears to us that a somewhat similar arrangement might have been possible for the library, especially noting the presence of bored piles, with consequent economies for the permanent works. 
A different method of working is the 'top down' method. We have normally used this where multi-storey construction is required above the ground floor. Did the authors consider other forms of temporary works in relation to the construction of the diaphragm walls and their relative costs?

\section{Authors' reply}

Space limitation has resulted in our omitting some details related to the construction process.

As mentioned in the paper, the new library building has a design life of 200 years. The lifespan was specified taking into consideration the effect of the severe environment of the coastal area on the concrete itself as well as on the steel reinforcement. Different international codes and standards were reviewed to select the most conservative conditions to achieve the required level of durability of concrete for such exposure conditions. Two degradation models were used: the first was the degradation of concrete by sulphates present in groundwater and soil, and the second was the degradation of reinforced concrete elements by corrosion of reinforcement due to chloride attacks. The design provisions for durability called for the use of high-performance concrete with a low water/ cement ratio, the use of high blastfurnace slag cement, the provision of thick concrete cover, good workmanship, and quality control of each step of construction. They also called for the designed reinforcement to be ready for cathodic protection when needed. In the library building all concrete elements in contact with soil, such as piles and diaphragm walls, were cast using high-performance and self-compacting concrete with a specified 28-day compressive strength of 45 MPa and actual 90-day compressive strength of more than $55 \mathrm{MPa}$. This concrete was made from $420 \mathrm{~kg} / \mathrm{m}^{3}$ of high blastfurnace slag cement with a free water/cement ratio of 0.37. Natural washed sand and gravel were used as fine and coarse aggregates. In these aggregates chloride content was not more than $0.03 \%$ by weight, and total chloride content in concrete was kept below $0 \cdot 15 \%$ of cement weight. The coefficient of permeability of the used concrete after 90 days was less than $1 \times 10^{-12} \mathrm{~m} / \mathrm{s}$. The concrete cover thickness for all concrete elements in contact with the soil was $150 \mathrm{~mm}$.

The thick raft was designed as a massive concrete element, therefore all precautions were taken to eliminate the heat of hydration, including the use of high blastfurnace slag cement containing 75\% slag and 25\% of ordinary Portland cement, and control of the fresh concrete temperature to be below $20^{\circ} \mathrm{C}$. The maximum difference of concrete temperature at the centre of the raft and at the upper surface of the raft was kept to around $15^{\circ} \mathrm{C}$.
Health monitoring of the structure was a key design element to ensure durability. The chloride penetration was monitored using an anode ladder system, which was embedded at different levels in different piles, diaphragm walls and capping beams. In addition, embedded reference electrodes were used to monitor the potential of reinforcement. Different types of instrumentation were used to monitor the chloride penetration by anode ladder system, corrosion of reinforcement by embedded reference electrodes, deformation in the piles and diaphragm walls during and after construction by using the inclinometer, and measurement of the strain in the concrete and steel reinforcement by sister strain gauges.

In addition to the use of impermeable concrete, two systems of waterproofing were installed and tested between the diaphragm wall and outer wall, and under the raft foundation. The first was a high-density polypropylene membrane of $2 \mathrm{~mm}$ thickness. The second system was a bentonite geotextile liner.

Owing to the important issue of durability, the authors will discuss the design for durability of the new Alexandria Library in a separate paper.

\section{REFERENCES}

1. EVES R. C. W. and CuRTIS D. J. Tunnel lining design and procurement. Proceedings of the Institution of Civil Engineers, Civil Engineering, 1992, Special Issue, Channel Tunnel, Part 1: Tunnels, 127-143.

2. ElliotT I. H., Odgard A. S. and CuRTIS D. J. Storebaelt Eastern Railway Tunnel: design. Proceedings of the Institution of Civil Engineers, 1996, Special Issue, Storebaelt Eastern Railway Tunnel, 1996, 114, Special Issue 1, 9-19.

3. LAU C. K. and Wong K. Y. Design and construction of the Lantau Link Bridges. Proceedings of the Institution of Civil Engineers, Civil Engineering, 1998, 126, Special Issue, Hong Kong International Airport, Part 2: Transport links.

4. American Concrete Institute. ACI Building Code. ACI, Farmington Hills, MI, 1990, ACI 318/318R-35.

5. BRITISH STANDARDS INSTITUTION. Concrete Part 1: Specification, performance, production and conformity. BSI, Milton Keynes, 2000, BS EN 206-1:2000.

6. WALKER M. (ed.). Guide to the Construction of Reinforced Concrete in the Arabian Peninsula. CIRIA/Concrete Society, Crowthorne, 2002.

7. Agar M., IRWIN ChILds F. and ChILdS F. I. Seaforth Dock, Liverpool: planning and design. Proceedings of the Institution of Civil Engineers, Part 1, 1973, 54, 255-274.

8. Holloway B. G. R., Feit M. J. and Wadsworth H. J. Passage gates for Seaforth Dock, Liverpool. Proceedings of the Institution of Civil Engineers, Part 1, 1973, 54, 239-254. 